\title{
Aplikasi Metode Seismik Refraksi dalam Menentukan Lapisan dan Tingkat Kekerasan Batuan di Bawah Permukaan Desa Medana Lombok Utara
}

\author{
${ }^{1}$ Syahrial Ayub, ${ }^{2}$ Muhammad Zuhdi, ${ }^{3}$ Joni Rokhmat \\ ${ }^{1,2,3}$ Program Studi Pendidikan Fisika, PMIPA, Universitas Mataram, Jl. Majapahit 62 \\ Mataram, Indonesia 83125 \\ Email: syahrial_ayub@unram.ac.id
}

\begin{tabular}{|c|c|}
\hline Article Info & Abstract \\
\hline $\begin{array}{l}\text { Article History } \\
\text { Received: October } 2020 \\
\text { Revised: December } 2020 \\
\text { Published: December } 2020\end{array}$ & \multirow{2}{*}{$\begin{array}{l}\text { The seismic refraction method is one of the geophysical methods which is } \\
\text { based on measuring the response of seismic waves in the soil that are fractured } \\
\text { along the soil and rock layers. One of the seismic refraction method } \\
\text { application is to determine the layers and rocks types below the surface. This } \\
\text { study uses a geophone as a catcher for seismic waves that are emitted below } \\
\text { the surface. The waves caught on the geophone are converted into seismic data } \\
\text { which can be read in a seismograph. Seismic data read by seismographs are } \\
\text { already in digital form and stored in the central unit PASI 16S24-P. The results } \\
\text { of the data analysis concluded that below the land surface of the village of } \\
\text { Medana, there were } 3 \text { rock layers with a thickness of the first layer } 3-4 \text { meters, } \\
\text { the second layer } 2-5 \text { meters and the third layer 10-17 meters. The first and } \\
\text { second layers are still in the form of soil (less compact), while the third layer is } \\
\text { in the form of rock (compact). The level of hardness (density) will be more } \\
\text { compact in linear to the depth, the more the depth will be the more compact the } \\
\text { rock. The depth in the form of hard rock starts from } 16 \text { meters to } 23 \text { meters } \\
\text { from the ground level of the village of Medana, Central Lombok. }\end{array}$} \\
\hline $\begin{array}{l}\text { Keywords } \\
\text { Refraction Seismic, } \\
\text { Subsurface, Geophone }\end{array}$ & \\
\hline Informasi Artikel & Abstrak \\
\hline $\begin{array}{l}\text { Sejarah Artikel } \\
\text { Diterima: Oktober } 2020 \\
\text { Direvisi: Desember } 2020 \\
\text { Dipublikasi: Desember } 2020\end{array}$ & \multirow{2}{*}{$\begin{array}{l}\text { Metode seismik refraksi merupakan salah satu dari metode geofisika yang } \\
\text { didasarkan pada pengukuran respon gelombang seismik dalam tanah yang } \\
\text { direfraksikan sepanjang lapisan tanah dan batuan. Salah satu aplikasi dari } \\
\text { metode seismik refraksi adalah menentukan lapisan dan jenis batuan di bawah } \\
\text { permukaan. Penelitian ini menggunakan geophone sebagai penangkap } \\
\text { gelombang seismik yang di pancarkan ke bawah permukaan. Gelombang yang } \\
\text { tertangkap di geophone diubah menjadi data seismik yang dapat dibaca dalam } \\
\text { seismograf. Data seismik yang terbaca oleh seismograf sudah dalam bentuk } \\
\text { data digital tersimpan di main unit PASI 16S24-P. Hasil analisis data } \\
\text { menyimpulkan bahwa di bawah permukaan tanah desa medana di temukan } 3 \\
\text { lapisan batuan dengan ketebalan lapisan pertama } 3-4 \text { meter, lapisan kedua } 2-5 \\
\text { meter dan lapisan ke tiga } 10-17 \text { meter. Lapisan pertama dan kedua masih } \\
\text { berupa tanah (kurang kompak) sedangkan pada lapisan ke tiga sudah berupa } \\
\text { batu (kompak). Tingkat kekerasan (density) akan semakin kompak sebanding } \\
\text { dengan kedalaman, semakin bertambahnya kedalaman akan semakin kompak } \\
\text { batuannya. Kedalaman yang sudah berupa batuan keras mulai dari } 16 \text { meter } \\
\text { sampai } 23 \text { meter dari permukaan tanah desa Medana Lombok Tengah. }\end{array}$} \\
\hline $\begin{array}{l}\text { Kata kunci } \\
\text { Seismik Refraksi, Bawah } \\
\text { Permukaan, Geophone }\end{array}$ & \\
\hline
\end{tabular}

Sitasi: Ayub, S., Zuhdi, M., \& Rokhmat, J. (2020). Aplikasi Metode Seismik Refraksi dalam Menentukan Lapisan dan Tingkat Kekerasan Batuan di Bawah Permukaan Desa Medana Lombok Utara. Kappa Journal, $4(2), 188-196$. 


\section{PENDAHULUAN}

Pembangunan hotel-hotel di daerah wisata seperti di desa medana Lombok Utara, membutuhkan survei bawah permukaan untuk mengetahui lapisan lapisan batuannya. Selain itu, penanaman kabel dan pipa-pipa lainnya di bawah permukaan tanah untuk berbagai keperluan seperti kabel telepon, kabel listrik, pipa air dan sebagainya menghendaki kemudahan pemasangan, keamanan dan keindahan lingkungan (Bulqis K, 2008). Ketidaktahuan batuan yang ada di bawah permukaan tanah seringkali menimbulkan masalah penggalian dan posisinya. Kedalaman pondasi bangunan juga perlu diperhatikan sesuai dengan jenis batuan di bawah permukaan, supaya pondasi yang dibuat kuat dan bangunan yang di atasnya juga akan kokoh. Untuk menyelesaikan masalah-masalah tersebut di atas, perlu dilakukan studi ke-geofisika-an. Metode seismik refraksi merupakan salah satu metode geofisika yang mempelajari gelombang seismik yang dipancarkan ke dalam bumi (Atmajaya, 2008). Gelombang seismik yang dipancarkan dipelajari karakteristiknya, seperti cepat rambat gelombang seismik tersebut. Pada prinsipnya metode ini memanfaatkan perambatan gelombang seismik di dalam bumi. Gelombang seismik merupakan gelombang elastik dan perambatannya tergantung pada sifat elastisitas batuan dan densitas batuan, sehingga dengan mengetahui cepat rambat gelombang seismik pada lapisan batuan, maka akan diketahui tingkat kekerasan batuan dan densitas batuan tersebut (Lubis, 2005). Ketika gelombang seismik menjalar menemui bidang batas antar lapisan, sebagian gelombang ini ada yang direfleksikan (dipantulkan) dan ada yang di refraksikan (dibiaskan) kemudian gejala fisisnya diamati dengan menangkap gelombang tersebut melalui geophone (Nakif dkk, 2013). Hal ini, akan diketahui nilai cepat rambat dan kedalaman lapisan berdasarkan perhitungan waktu tempuh gelombang antara sumber getaran (source) dan penerima (geophone). Waktu yang diperlukan gelombang seismik untuk merambat pada lapisan batuan bergantung pada besarnya cepat rambat yang dimiliki pada medium yang dilaluinya. Metode seismik refraksi adalah salah satu metode yang menerapkan hukum-hukum fisika dalam analisinya. Hukumhukum yang digunakan pada metode seismik refraksi ini adalah hukum Snellius, azas Fermat, dan hukum Huygens (Sismanto, 1999). Hukum pembiasan (refraksi) Snellius menjelaskan hubungan sudut datang dan sudut bias terhadap cepat rambat gelombang di dalam medium. Azas Fermat menjelaskan cara penjalaran gelombang dari satu titik ke titik selanjutnya yang melewati medium tertentu dengan lintasan terpendek (waktu minimum). Hukum Huygen menjelaskan cara penjalaran gelombang dengan melewati satu titik dan akan membuat titik tersebut menjadi sumber gelombang baru dan seterusnya sehingga terjadi penjalaran gelombang. Sifat-sifat fisik batuan terkait dengan cepat rambat gelombang seismik refraksi untuk menentukan kedalaman batuan dasar, litologi batuan dasar (bed rock), sesar, dan kekerasan batuan (Gardner, 1974). Cepat rambat gelombang yang diperoleh akan dikonsultasikan pada tabel hubungan cepat rambat gelombang seismik dengan tingkat kekerasan batuan yang akan diindikasikan dengan densitas batuan (Zulhelmi, 2018). Lapisan bawah permukaan tanah memiliki sifat-sifat fisis yang variatif. Elastisitas dan tingkat kekerasan batuan adalah salah satu sifat fisis lapisan bawah permukaan tanah. Tingkat kekerasan batuan menandakan kekompakan (cohesiveness), suatu batuan dan biasanya dinyatakan dalam bentuk compressive fracture strenght (tekanan maksimum yang mampu ditahan oleh batuan untuk mempertahankan diri dari terjadinya rekahan). Besarnya fracture strenght dipengaruhi oleh densitas dan kekompakan batuan. Disamping itu, densitas dan kekompakan batuan juga dipengaruhi oleh elastisitas batuan (Nurdiyanto dkk, 2011) 


\section{METODE}

Kegiatan penelitian ini dilaksanakan di desa Medana kabupaten Lombok Utara propinsi Nusa Tenggara Barat yang secara geografis terletak -8,363656 LS dan 116,122766 BT. Lokasi penelitian dapat dilihat pada gambar 1 di bawah ini:

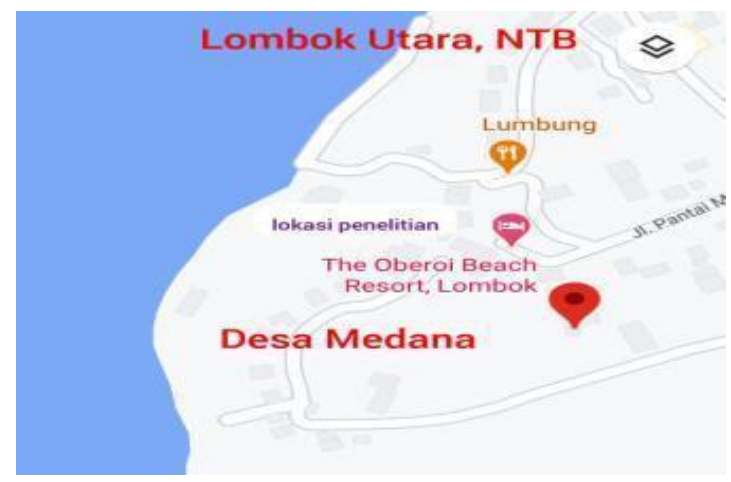

Gambar 1 : Lokasi Penelitian Desa Medana Lombok Utara, NTB

Peralatan yang digunakan dalam kegiatan penelitian ini terdiri dari Seismograph PASI 16S24_P, geophone cable, trigger cable, power supply 12 Volt, palu godam (sledgehammer) dan landasan pukul (plat besi), geophone 48 buah, dan peralatan lainnya seperti earphone, meteran, handy talk, global positioning system (GPS), sarung tangan, payung, dan log book. Berikut pada gambar 2 diperlihatkan peralatan utama yang digunakan pada penelitian ini:

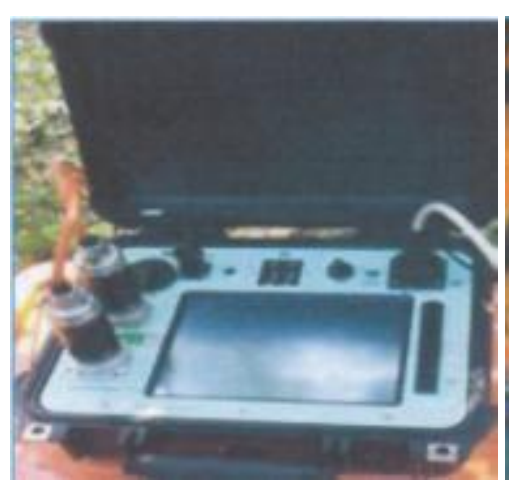

(a)

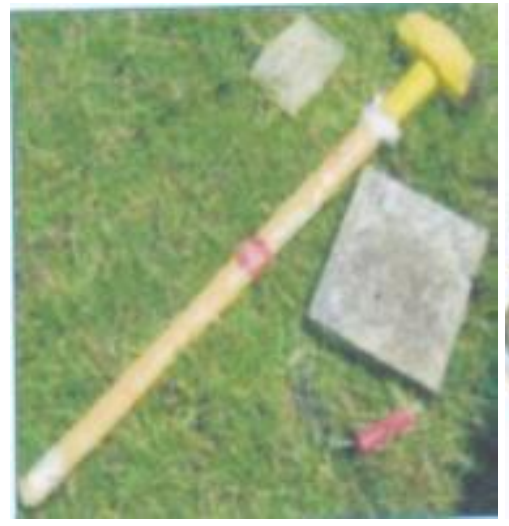

(d)

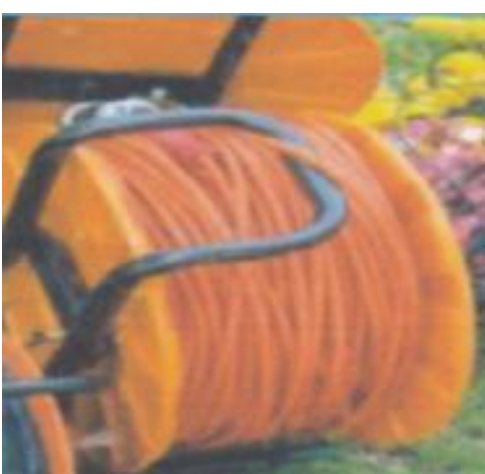

(b)

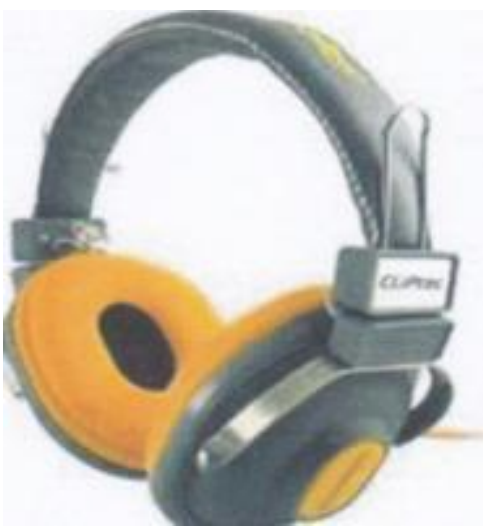

(e)

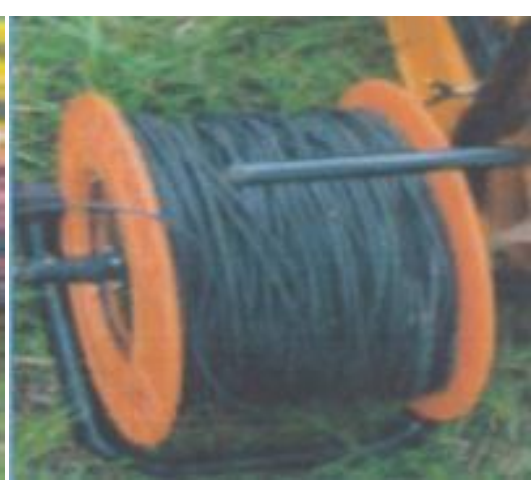

(c)

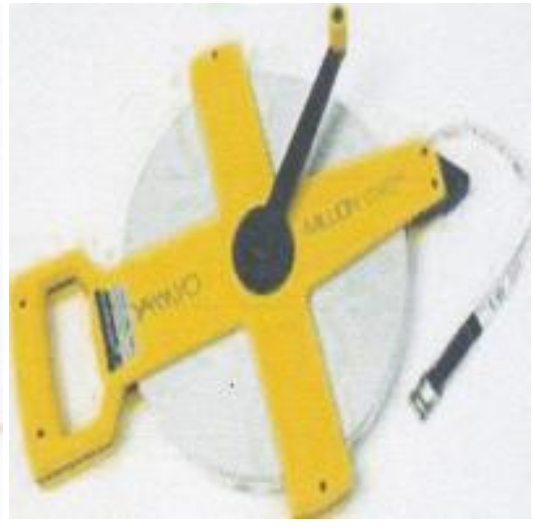

(f)

Gambar 2: (a) seismograph, (b) kabel geophone, (c) Kabel Trigger, (d) Palu dan Plat Besi (e) earphone, (f) meteran 
Panjang lintasan pada penelitian seismik refraksi ini adalah $96 \mathrm{~m}$ dengan jarak antar geophone adalah 2 meter, jadi dalam satu lintasan pengukuran terdapat 48 buah geophone yang ditancapkan. Gambar 3 memperlihatkan skema lintasan dan pemasangan geophone pada penelitian ini.

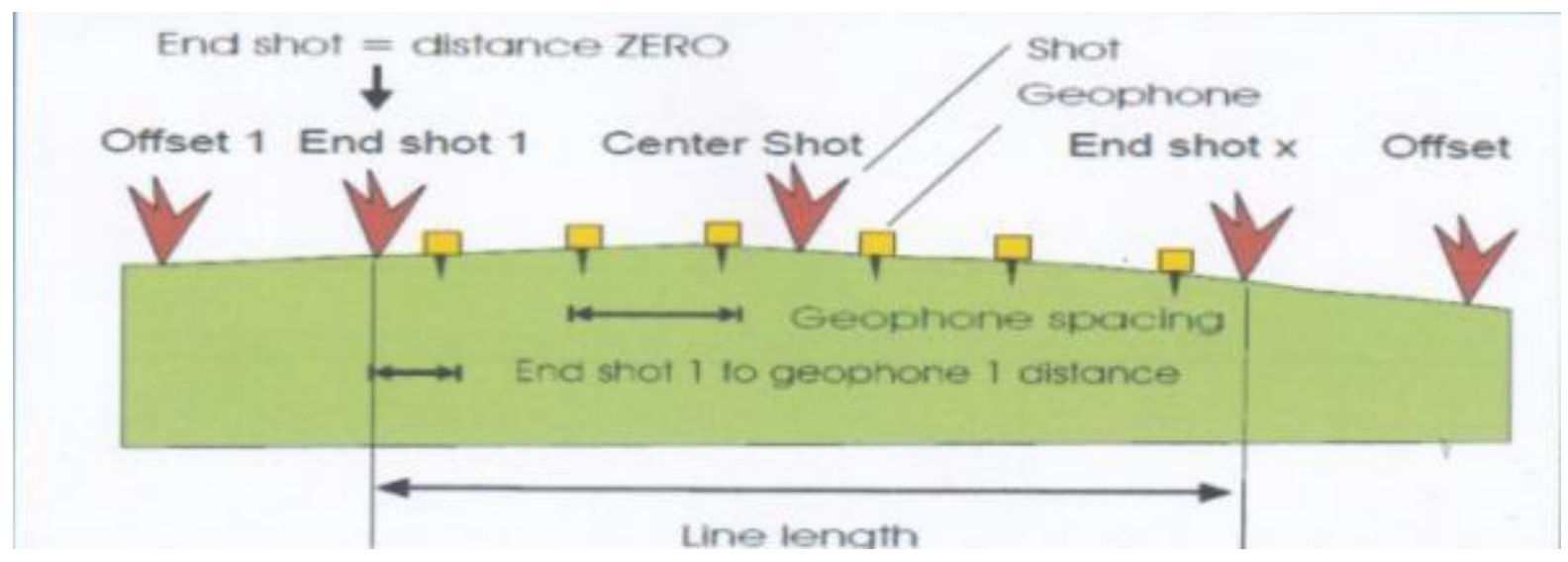

Gambar 3 : Skema Lintasan dan Pemasangan Geophone

Berdasarkan skema ini, akuisisi data seismik refraksi dilakukan dengan menggunakan model bentang garis (inline). Pengolahan data seismik refraksi menggunakan software SeisImager dengan program WinSism V.12 dan Plotrefa dengan metode pengolahan dengan intercept time. Untuk mendapatkan nilai cepat rambat terlebih dahulu dilakukan proses editing geometri kemudian ditampilkan dalam penampang seismik. Data penampang seismik ini sebelumnya difilter terlebih dahulu menggunakan Low Pass Filter (LP Filter) untuk menampilkan data yang jelas dan mengurangi noise. LP Filter ini penting dilakukan untuk memastikan data yang diolah benar merupakan data seismik dari sumber yang diberikan (Susilawati, 2004). Setelah itu data dipicking pada gelombang pertamanya (fistbreak) untuk mendapatkan waktu tiba (time break) dan ditampilkan dalam kurva waktu tempuh (travel time) yang kemudian diinterpretasikan. Tingkat kekerasan batuan diperoleh dengan menggunakan hubungan antara densitas dan cepat rambat gelombang yang diiperlihatkan pada persamaan (1) dan dikenal sebagai hukum Gardner (Gardner, G.H.F., 1974)

$$
\rho=\alpha V^{1 / 4}
$$

$\rho$ adalah densitas $\left(\mathrm{gram} / \mathrm{cm}^{3}\right), \alpha$ adalah konstanta yang besarnya 0,31 dan $\mathrm{V}$ adalah cepat rambat gelombang $(\mathrm{m} / \mathrm{s})$.

\section{HASIL DAN PEMBAHASAN}

Sesuai pada metode penelitian, data diambil pada satu lintasan dengan panjang 96 meter dengan jarak antar geophone 2 meter sehingga dalam lintasan ini terdapat 48 buah geophone. Berikut memperlihatkan penjalaran gelombang seismik di bawah permukaan dengan 5 sumber getaran dari palu seismik (5 shoot). 


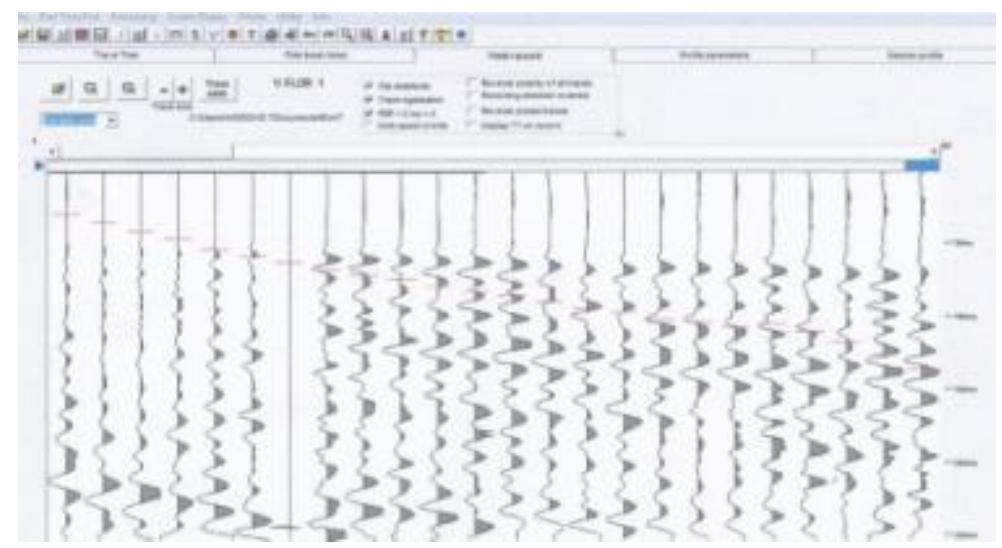

Gambar 4 : Penjalaran Gelombang Seismik di Bawah Permukaan dari Shoot 1

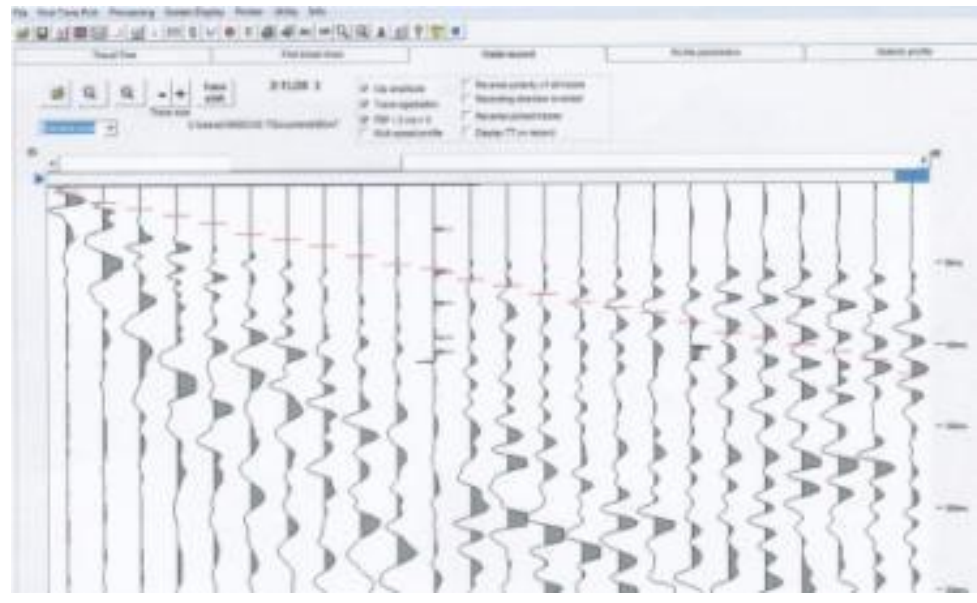

Gambar 5 : Penjalaran Gelombang Seismik di Bawah Permukaan dari Shoot 2

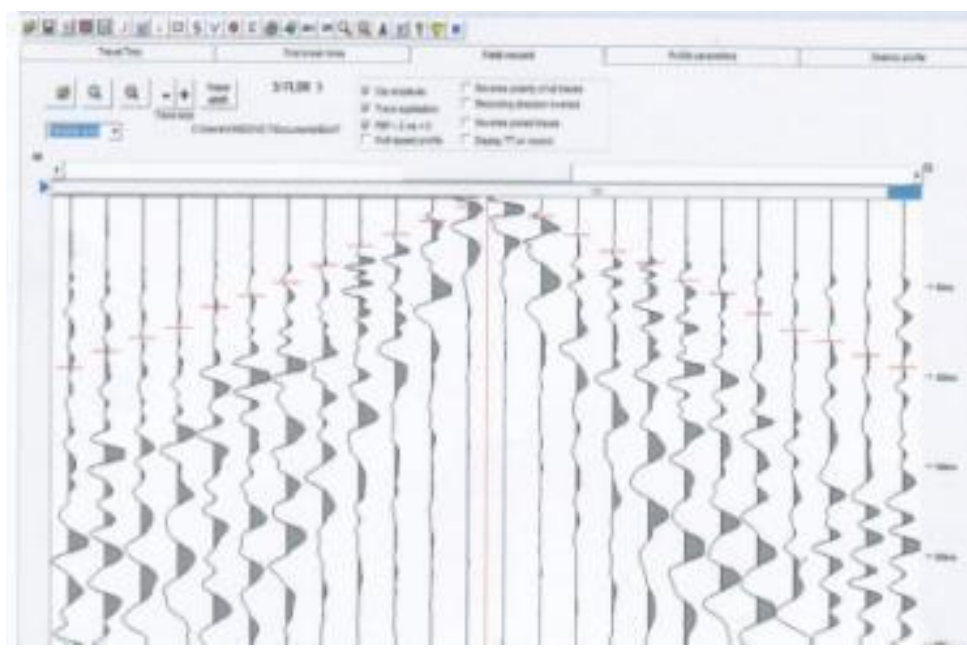

Gambar 6 : Penjalaran Gelombang Seismik di Bawah Permukaan dari Shoot 3 


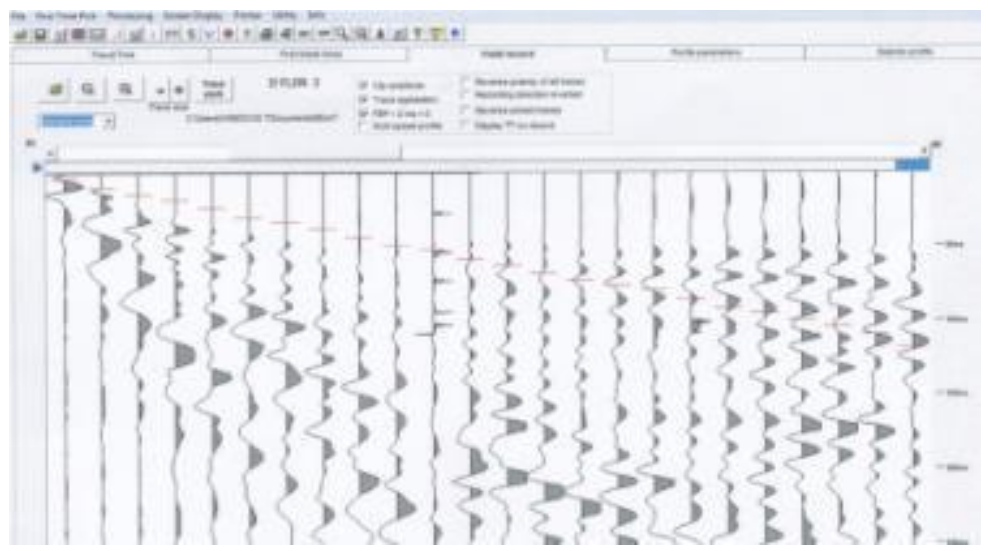

Gambar 7 : Penjalaran Gelombang Seismik di Bawah Permukaan dari Shoot 4

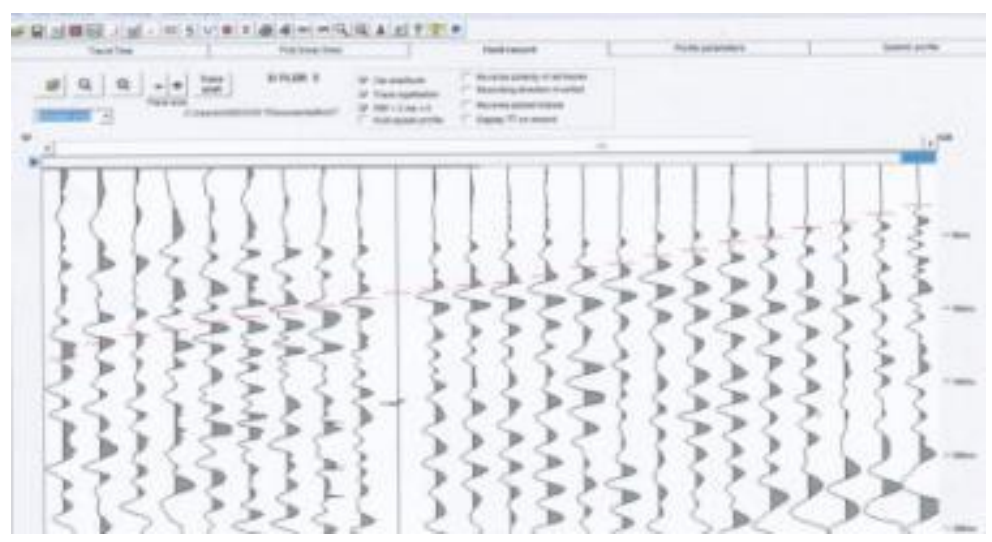

Gambar 8 : Penjalaran Gelombang Seismik di Bawah Permukaan dari Shoot 5

Menggunakan software WinSism V.12 dan Plotrefa didapatkan data cepat rambat gelombang seismik yang merambat di bawah permukaan tanah Medana kabupaten Lombok Utara.
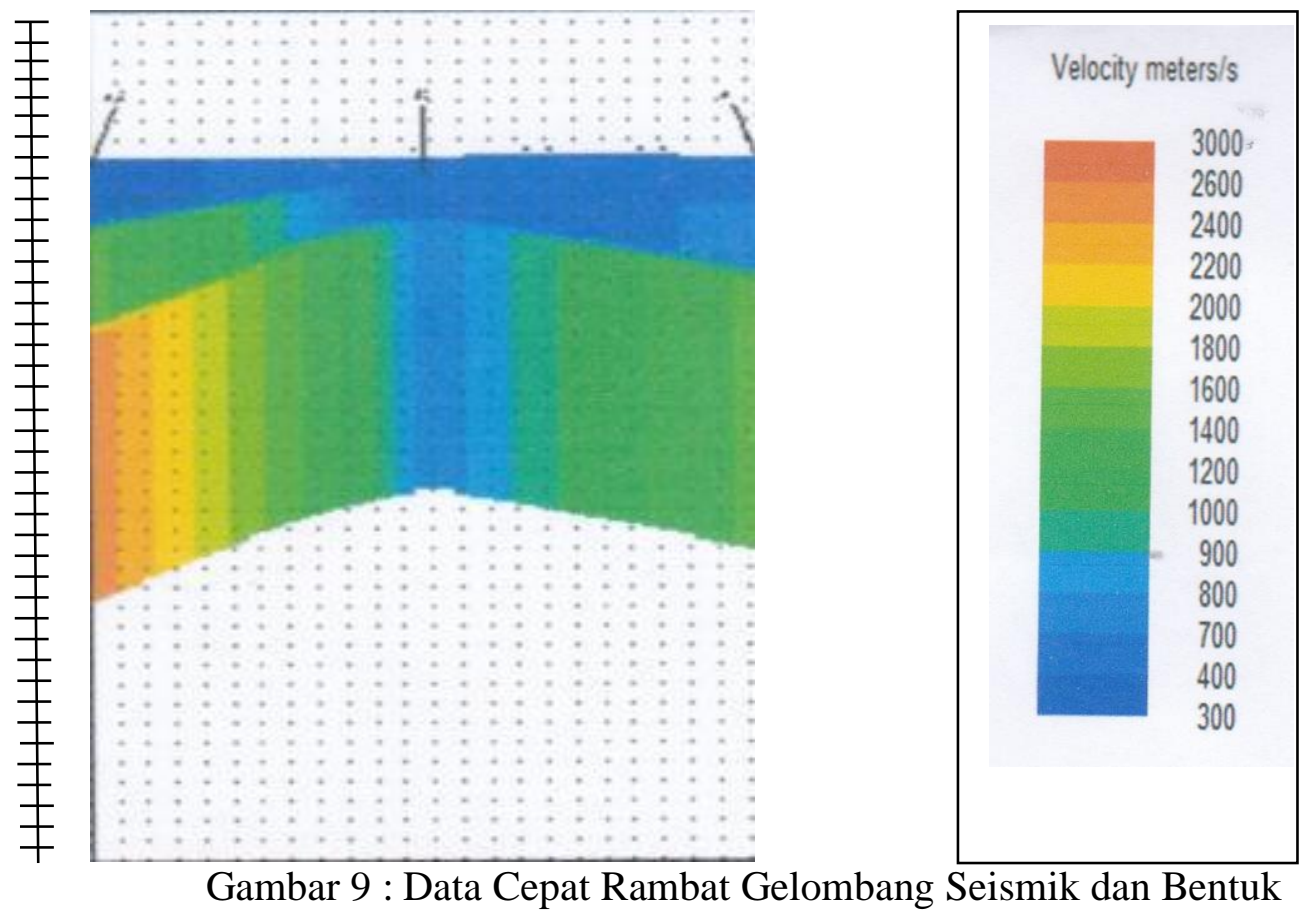
Lapisan diBawah Permukaan 


\section{Analisis Interpretasi Seismik Refraksi}

Pada lintasan yang dilakukan pengukuran dengan panjang lintasan 96 meter dengan jarak antar geophone 2 meter, hasil interpretasinya menunjukkan bahwa terdeteksi 3 lapisan pada penelitian ini. Nilai cepat rambat gelombang seismik didapatkan dari $300 \mathrm{~m} / \mathrm{s}$ sampai $700 \mathrm{~m} / \mathrm{s}$ dengan kedalaman sampai 10 meter dari permukaan tanah. Lapisan pertama dengan cepat rambat gelombang seismik $300 \mathrm{~m} / \mathrm{s}$ sampai $700 \mathrm{~m} / \mathrm{s}$ dengan ketebalan lapisan 3-4 meter. Lapisan kedua dengan ketebalan 2-5 meter terdiri dari 2 bagian cepat rambat gelombang yaitu sepanjang 32 meter mendatar cepat rambatnya $1000 \mathrm{~m} / \mathrm{s}$ sampai $1400 \mathrm{~m} / \mathrm{s}$ dan sepanjang 64 meter mendatar cepat rambatnya $300 \mathrm{~m} / \mathrm{s}$ sampai $900 \mathrm{~m} / \mathrm{s}$. Ini mengindikasikan lapisan ini terdiri dari 2 jenis batuan dengan tingkat kekerasan yang berbeda. Lapisan ke tiga dengan ketebalan 10-17 meter didapatkan cepat rambat gelombang seismiknya lebih bervariasi lagi yang mengindikasikan terbentuk dari 4 jenis batuan dengan tingkat kekerasan yang berbeda beda. Cepat rambat gelombang seismik pada lapisan ke tiga ini adalah sepanjang 26 meter mendatar cepat rambatnya $1800 \mathrm{~m} / \mathrm{s}$ sampai $3000 \mathrm{~m} / \mathrm{s}$, sepanjang 24 meter mendatar cepat rambatnya $1000 \mathrm{~m} / \mathrm{s}$ sampai $1600 \mathrm{~m} / \mathrm{s}$, sepanjang 18 meter mendatar cepat rambatnya $300 \mathrm{~m} / \mathrm{s}$ sampai $900 \mathrm{~m} / \mathrm{s}$ dan sepanjang 28 meter mendatar cepat rambatnya $1000 \mathrm{~m} / \mathrm{s}$ sampai $1400 \mathrm{~m} / \mathrm{s}$. Cepat rambat gelombang mengidentifikasikan jenis batuan yang dilewatinya. Nilai cepat rambat gelombang yang didapat pada perhitungan dipengolahan data di penelitian ini dikonsultasikan pada tabel cepat rambat gelombang seismik $\left(\mathrm{V}_{\mathrm{p}}\right)$ pada batuan (Telford,1990).

Tabel 1 : Cepat Rambat Gelombang Seismik $\left(\mathrm{V}_{\mathrm{p}}\right)$ pada Batuan

\begin{tabular}{ccc}
\hline & Material & Cepat Rambat $\left(\mathrm{V}_{\mathrm{p}}\right)(\mathrm{m} / \mathrm{s})$ \\
\hline \multirow{4}{*}{ Tanah } & alluvial & $500-2100$ \\
& lempung & $1100-2500$ \\
& loss & $300-600$ \\
pasir & $200-2000$ \\
& napal bongkah & $400-1700$ \\
\hline \multirow{4}{*}{ Batu } & granit & $4600-6000$ \\
& gaabro, dolerite, basalt & $5000-6700$ \\
& batu pasir, serpih & $1400-4500$ \\
& batu kapur, lembek & $1700-4200$ \\
& batu kapur, kokoh & $2800-6400$ \\
marmer & $5700-6400$ \\
& sabak & $3600-4400$ \\
& skis, gneis & $3500-7500$ \\
\hline
\end{tabular}

\section{Hasil Analisis dan Perhitungan Densitas}

Hasil interpretasi seismik refraksi mendeteksi permukaan bawah tanah desa Medana Lombok Utara terdiri dari 3 lapisan atau memiliki struktur litologi 3 lapis. Tabel 2 memperlihatkan hasil perhitungan tingkat kekerasan (densitas) litologi batuan hasil seismik refraksi.

Tabel 2 : Tingkat Kekerasan (Densitas) Litologi Batuan Hasil Seismik Refraksi di Desa Medana Lombok Utara

\begin{tabular}{cccc}
\hline Ketebalan $(\mathrm{m})$ & $\mathrm{V}_{\mathrm{p}}(\mathrm{m} / \mathrm{s})$ & $\rho(\mathrm{gr} / \mathrm{cc})$ & Jenis Batuan \\
\hline $3-4$ & $300-900$ & $\mathbf{1 , 2 9}-\mathbf{1 , 6 9}$ & top soil, pasir dan kerikil tak \\
& & & jenuh \\
$2-5$ & $1000-1400$ & $\mathbf{1 , 7 4}-\mathbf{1 , 8 9}$ & alluvium, pasir jenuh \\
$10-17$ & $1800-3000$ & $\mathbf{2 , 0 2}-\mathbf{2 , 2 9}$ & batu kapur kokoh, batu pasir \\
\hline
\end{tabular}


Hasil penelitian tingkat kekerasan batuan (density) seperti yang didapatkan pada tabel 2 menunjukkan semakin bertambahnya kedalaman maka batuannya semakin kompak.

\section{KESIMPULAN}

Hasil analisis data menyimpulkan bahwa di bawah permukaan tanah desa medana di temukan 3 lapisan batuan dengan ketebalan lapisan pertama 3-4 meter, lapisan kedua 2-5 meter dan lapisan ke tiga 10-17 meter. Lapisan pertama dan kedua masih berupa tanah (kurang kompak) sedangkan pada lapisan ke tiga sudah berupa batu (kompak). Tingkat kekerasan (density) akan semakin kompak sebanding dengan kedalaman, semakin bertambahnya kedalaman akan semakin kompak batuannya. Kedalaman yang sudah berupa batuan keras mulai dari 16 meter sampai 23 meter dari permukaan tanah desa Medana Lombok Tengah.

\section{SARAN}

Hasil penelitian menemukan batuan keras baru ditemukan pada kedalaman 16 meter dari permukaan tanah desa Medana Lombok Utara. Bagi masyarakat atau pengembang yang akan membangun gedung, hotel ataupun rumah harus menggali pondasi sampai ditemukan batuan keras ini supaya pondasi bangunan yang dibuat kokoh dan kuat.

\section{UCAPAN TERIMA KASIH}

Terima kasih kami ucapkan kepada FKIP Universitas Mataram yang telah memberikan bantuan dana dalam kegiatan penelitian ini dan memberikan bantuan dana untuk peminjaman satu set alat seismik. Terima kasih juga kami ucapkan kepada Laboratorium fisika FMIPA Universitas Mataram yang telah menyediakan peralatan seismik kepada kami. Semoga apa yang sudah diberikan dan difasilitasi membawa berkah bagi perkembangan ilmu pengetahuan khususnya ilmu fisika dan terapannya.

\section{DAFTAR PUSTAKA}

Atmajaya. (2008). Investigasi Sub-Permukaan Tanah untuk Perencanaan Jalan Menggunakan Survei Pembiasan Seismik. Yogyakarta : Universitas Muhammadyah Yogyakarta.

Bulqis K., Teti Z., (2008). Aplikasi Metode Geolistrik Tahanan Jenis Konfigurasi WennerSchlumberger untuk Survey Pipa Bawah Permukaan. Jurnal Teknik Elektro Universitas Mataram, 7(2), 84-91.

Gardner, G.H.F., Garder, L.W., and Gregory, A.R. (1974). Formation Velocity and Density the Diagnostic Basic for Stratigraphic Traps. Jurnal Geophysics, 39(1), 770-780.

Lubis, A.M. (2005). Analisis Kecepatan Gelombang Seismik Bawah Permukaan di Daerah yang Terkena Dampak Gempa Bumi 4 Juni 2000 (Studi Kasus : Kampus Universitas Bengkulu). Jurnal Gradien, 1(2), 69-73.

Nakif, N., Darsono, Sorja K., (2013). Penentuan Tingkat Kekerasan Batuan Menggunakan Metode Seismik Refraksi di Jatikuwung Karang Anyar. Indonesian Journal of Applied Physics, 3(1), 29-35.

Nurdiyanto, B. (2011). Penentuan Tingkat Kekerasan Batuan Menggunakan Metode Seismik Refraksi. Jurnal Meteorologi dan Geofisika, 12(3), 211-220.

Susilawati. (2004). Seismik Refraksi (dasar teori dan akuisisi data). USU Digital Library. 
Sismanto. (1999). Eksplorasi dengan Menggunakan Seismik Refraksi. Yogyakarta: Gadjah Mada University Press.

Telford, W.M., Geldart, L.P. Sheriff, R.E. (1990). Applied Geophysic (Vol.1). Cambridge University Press.

Zulhelmi, Rustan E., Abdullah. (2018). Penentuan Kerapatan Batuan Menggunakan Metode Seismik Refraksi di Desa Dalaka Kecamatan Sindue Kabupaten Donggala. Jurnal Universitas Tadulako, 17(1), 57-64. 